Indexed by

\title{
AN EXTENSIVE SOLUTION TO PREVENT WAX
Scopus
DEPOSITION FORMATION IN GAS-LIFT WELLS
}

Crossref

\section{Thang Nguyen Van}

Department of Oil and Gas Field Development and Operation, Oil and Gas Faculty, Saint Petersburg Mining University, Saint Petersburg,

Russia, 199106

\author{
Aleksandr Nikolaevich \\ Aleksandrov \\ Department of Oil and \\ Gas Field Development \\ and Operation, Oil and Gas \\ Faculty, Saint Petersburg \\ Mining University, Saint \\ Petersburg, \\ Russia, 199106
}

\author{
Mikhail Konstantinovich \\ Rogachev \\ Department of Oil and \\ Gas Field Development \\ and Operation, Oil and Gas \\ Faculty, Saint Petersburg \\ Mining University, Saint \\ Petersburg, \\ Russia, 199106
}

Key words: high-wax oil, operation of gas-lift wells, wax appearance temperature, optimal composition, associated petroleum gas doi:10.5937/jaes0-31307

Cite article:

Nguyen Van T., Nikolaevich Aleksandrov A., Konstantinovich Rogachev M. (2022) AN EXTENSIVE SOLUTION TO PREVENT WAX DEPOSITION FORMATION IN GAS-LIFT WELLS, Journal of Applied Engineering Science, 20(1), 264 - 275, DOI:10.5937/ jaes0-31307

Online aceess of full paper is available at: www.engineeringscience.rs/browse-issues 


\title{
AN EXTENSIVE SOLUTION TO PREVENT WAX DEPOSITION FORMATION IN GAS-LIFT WELLS
}

\author{
Thang Nguyen Van*, Aleksandr Nikolaevich Aleksandrov, Mikhail Konstantinovich Rogachev \\ Department of Oil and Gas Field Development and Operation, Oil and Gas Faculty, Saint Petersburg Mining \\ University, Saint Petersburg, Russia, 199106
}

In recent years, an insurmountable problem in high-wax oil production has been the intensive formation of organic deposits in the bottom-hole zone of the formation, downhole and surface equipment, leading to a dramatic loss in wells production, transportation capability, and subsequently has a detrimental effect on efficiency. Gas-lift is a widely used method, where compressed high-pressure gas is injected through the tubing annulus. Consequently, the current fluid level in the annulus decreases and increases in the tubing string. The compressed gas enters the tubing through gas-lift valves, mixing with the liquid. During production, changes in pressure, temperature, and fluid composition along the well bore highly depend upon the compressed gas injected into the well. At temperatures below the wax appearance temperature, organic wax crystals will form either in bulk volumes of fluid or on cold surfaces of equipment, consequently, covering the surface. Wax formation is a hazardous and costly task in the oil and gas industry, especially when operating gas-lift wells. Hence, the prevention of wax formation in gas-lift wells is of utmost importance. Although, numerous methods have been implemented to handle the wax formation problem in recent decades, questions concerning their economic viability as well as their effectiveness remain relevant. In this paper, a complete algorithm for determining changes in the oil component composition in a gas-lift well during the injection of associated petroleum gas is detailed. The obtained results play a pivotal role in the study of wax deposition. A technological scheme has been developed to prevent wax deposit formation in the tubing strings during gas-lift well operation. A simulation using the introduced process and technology has been run, and an observed result obtained. After running the simulation, we determined the optimal composition of the associated petroleum injection gas based on the required flow rate of the working agent and the lowest value of the wax appearance temperature. This method offers potential solutions to increasing gas-lift well production efficiency under complex wax formation conditions.

Key words: high-wax oil; operation of gas-lift wells; wax appearance temperature; optimal composition; associated petroleum gas

\section{INTRODUCTION}

Nowadays, the gas-lift method of well operation is one of the most comprehensive and efficient choices in offshore oil and gas field development $[1,2]$. Throughout the well production, if the reservoir energy is not sufficient to lift the liquid from the bottom to the well's surface, it is highly recommended to switch to the artificial oil production methods. Compressed high-pressure gas is injected into the tubing annulus. Subsequently, the current fluid level in the annulus will decrease, and in the tubing, it will increase. The compressed gas enters the tubing through gas-lift valves, mixing with the liquid. As a result, the density of the mixture will decrease. In this way, the mixture will begin to rise to the surface [3-5]. Flow assurance is risky and challenging for productive wells. One of the insurmountable problems in high-wax oil production is asphalt-resin-paraffin deposits (ARPD) in the bottom-hole zone of the formation, downhole and surface equipment, which leads to a dramatic loss regarding wells production, transportation capability, and subsequently has a detrimental effect on efficiency. During oil production, the formation of wax deposits also affects the status quo of the fluid flow. Furthermore, the viscosity of crude oil will increase, which consequently causes high demands in energy consumption for pumping processes, and as a result, the wax formation is the critical factor influencing the loss of efficiency [6-9]. The wax is composed of heavy hydrocarbons, the carbon numbers that change from 18 to 30 , known as paraffin wax, which is mixture of linear and branched saturated hydrocarbons, and saturated cyclic naphthenic hydrocarbons with carbon numbers from 31 to 65 . These molecules contain some cyclic and aromatic hydrocarbons. Paraffin wax can exist in different phases, either gas, liquid, or solid, subject to the temperature and pressure of a specific condition [10-13]. At temperatures bellows the wax appearance temperature, hereinafter referred to as the WAT, crystals of organic wax will form either in the bulk fluid or on cold surfaces of equipment, consequently fouling the surface. The authors $[14,15]$ proposed that the WAT is the primary factor influencing the wax formation process. Additionally, several factors also influence the wax precipitation, such as the operating pressure, the amount of dissolved, and the compressed injection gases. During the production, with a decrease in the operating pressure bellows the bubble point, the dissolved gas will liberate from the oil, which leads to an increase in the probability of wax deposition [16-18]. Studying the wax 
deposition process in gas-lift wells is a complicated task. Several factors influence it, such as the amount of compressed injection gas, properties of the multiple phases, and interactions between phases. Accordingly, the beforementioned factors have a crucial role in developing a mathematical model to study wax precipitation in gaslift wells. Nevertheless, many conventional studies have either overlooked them or obtained them empirically due to the difficulties in including those key factors when developing a model. As a result, applying the conventional model can lead to substantial errors when studying the gas-lift process. Moreover, most of the mathematical models studying wax precipitation have been developed based on the thermodynamic phase equilibrium relations [19-21]. In these models, the authors supposed that the fugacities must be counted because the WATs are identical for a pure substance, whereas they vary significantly for a mixture [22-24]. Therefore, it is indispensable to consider all the aspects mentioned above while studying the wax formation process in gas-lift well production. Prevention of wax formation in gas-lift wells is vital in the petroleum industry. Several well-known methods have been applied to cope with wax the formation problem. Mechanical-removal methods are the most conventional to be applied in offshore oil field development. The authors $[25,26]$ showed that scrapers and cutters could be utilized to remove wax precipitated on tubing surfaces. Additionally, paraffin wax can be removed by scraping from the tubing wall while the well is still working. Although these methods are reasonably priced, one of the principal disadvantages is the plugging of perforations within wells, given the fact that scraped paraffin circulates through the well annulus. Furthermore, the wireline scrapers can get stuck in wells during post-cleaning operations $[27,28]$. The authors also suggested that the efficiency in gas-lift wells might be enhanced by using free pistons to remove organic wax deposits from the tubing string. The utilization of chemical inhibitors for remediation of wax formation in the oil and gas industry has been studied by many researchers [29-31]. Wax inhibitors are added to high wax oils to reduce problems concerning lifting a fluid from the bottom - hole to the surface of a well. Wax inhibitors consist of wax-crystal modifiers, detergents, and dispersants. The main disadvantage of using chemical inhibitors is that they must be used before the bulk temperature of crude oil drops below the WAT. There are several thermal techniques of wax mitigation, such as hot oiling/ watering and thermal coatings that have been applied in offshore oil and gas fields [32-34]. Hot oiling or hot watering is a method of injecting hot oil or hot water into wells in an attempt to remediate wax deposits on tubing surfaces. The most significant advantage is that the method is known for its simplicity and does not always require complicated instrumentation. In addition to that, other benefits of this method could be its ease of application, low costs, and immediate results to temperature-related problems. Nevertheless, the method's effectiveness is highly contingent on the location, where wax deposits occur in the tubing string. Nonetheless, since the heat capacity of the injected liquid is considerably lower than the well's heat capacity, the liquid starts losing its heat capacity, given that heat convection and conduction processes begin inside the well. Furthermore, hot oil injection may cause formation damage over time. Consequently, the effectiveness of the method might decrease when the depth of wax formation is considerably large [35-37]. Chemical solvents are employed when oils are susceptible to surfactants or produced water with a high concentration of dissolved solid particles. The well-known chemical solvents to dissolve wax deposits are carbon tetrachloride, carbon disulfide, kerosene, and diesel oil [38-41]. The most significant advantage of using chemical solvents is their pricing and the fact that they do not always require complicated instrumentation. However, this method is useful only for a specific type of wax deposit with a range of molecular weight, contingent upon pressure and temperature [42, 43]. This paper's novelty is to provide a complete algorithm for determining changes in the oil component composition in a gas-lift well during the injection associated petroleum gas. The obtained results play a pivotal role in studying the wax deposition in gas-lift wells. A technological scheme has been developed to prevent wax deposit formation in the tubing strings during gas-lift well operation. The optimal composition of the injected gas has been determined to increase gas-lift well production efficiency under complicated wax formation conditions. A simulation using the introduced process and technology has been run, and an observed result obtained.

\section{METHODOLOGY}

The first step is to develop a complete algorithm for determining changes in the oil component composition during the gas injection process. The second step is to propose a technological scheme for a method of mitigating wax deposit formation. The calculated parameters are required data provided by the laboratory results of studying physicochemical properties of high-wax oil in Vietnam's Dragon field. The changes in the oil's component composition presented in this work derive from using the Python software product through the process of modeling the proposed algorithm. The temperature contribution is a result of modeling the production of the gas lift well using the PIPESIM software package.

\section{RESULTS AND DISCUSSION}

The Dragon deposit is located off the southern coast of Vietnam. The first commercial oil flow from the Lower Miocene sediments was obtained in July 1985 in the exploratory well R-1. According to the data [2], 24 explorations, 3 pre-productions, and 70 production wells were drilled within the Dragon field. The geological section is represented by igneous and metamorphic rocks of the basement (pre-Cenozoic age) and terrigenous sediments of Paleogene, Neogene, and Quaternary. Oil and 
gas condensate deposits have been found in the terrigenous sediments of the Lower Miocene, Upper and Lower Oligocene, and fractured-cavernous basement rocks. Highly productive oil deposits are mainly confined to the fractured-cavernous basement. Deposits in terrigenous sediments have complex structures. They are classified as stratal vaulted, lithological, and tectonically screening. The oil-water contact of oil deposits is horizontally positioned in the sedimentary cover and the basement. The oil from the Dragon field's basement formation is high-wax (wax content up to $27.00 \%$ by weight), which is characterized by a high intensity of wax deposits formation. The wax appearance temperature is $58^{\circ} \mathrm{C}$. The reservoir temperature is $131^{\circ} \mathrm{C}$, and the formation pressure is $18,5 \mathrm{MPa}$.

\section{A complete algorithm to determine changes in the oil's component composition during the produced petroleum gas injection}

Firstly, it has been noted that the properties of a gas mixture depend on its component composition. In the previous study, the authors [2] showed that studying the wax deposition process in gas-lift wells is a daunting task. Several factors influence it, such as the amount of compressed injection gas, properties of the multiple phases, and interactions between phases. Accordingly, the beforementioned factors have a crucial role in developing a mathematical model to study wax precipitation in gaslift wells. Nevertheless, many conventional studies have either overlooked them or obtained them empirically due to the difficulties in including those key factors when developing a mathematical model. As a result, applying the conventional model can lead to substantial errors when studying the gas-lift process. Most of the mathematical models studying wax precipitation have been developed based on the thermodynamic phase equilibrium relations [44 - 47]. In these models, the authors supposed that the fugacities must be counted because the WATs are identical for a pure substance, whereas they vary significantly for a mixture. It has been acknowledged that in the multi-component system, the tendency of components to escape between the liquid and gas phase are described by the equilibrium ratio $\mathrm{Ki}$. In other words, the $\mathrm{Ki}$ ratio represents the interaction between phases and has a significant impact on the gas properties as a whole. Furthermore, the K-value can be perceived as a function of pressure $\mathrm{P}$, temperature $\mathrm{T}$, and the hydrocarbon mixture's properties. In many conventional studies, the changes in oil component composition have been omitted. Moreover, in practice, the traditional model for gaslift wells was obtained empirically (piecewise linear or quadratic). Although an empirical performance correlation can be quickly formed, which supports the combined problems' solution, it cannot illustrate all crucial changes in different reservoir conditions, especially in the gas injection process. Additionally, the applicability of conventional models is limited because the mixture properties and the pressure drop along the wellbore are highly composition-dependent, which are often overlooked in those models. Hence, applying the conventional model can lead to substantial errors when studying the gas-lift process. Two fundamental factors must be taken into account when developing a mathematical model to study a gas-lift well production. First, the gas-lift process is inherently transient, and a proposed model should consider all the changes in the wellbore or the tubing string. Second, the gas-lift process is highly composition-dependent. Since the oil and gas compositions in gas-lift wells are varied, the wax appearance temperature is also variable. Thus, a rational approach to predicting the phase behavior is a fully compositional description method in which all of the aforementioned factors are considered. Based on the previous model introduced by the authors [2], a complete highly-accurate algorithm has been developed, providing a highly accurate mathematical model to study the wax formation process in a gas-lift well. The blend composition of the reservoir oil and injected petroleum gas are given in table 1.

Table 1: Blend composition of the reservoir oil and injected petroleum gas (mole fraction, \%)

\begin{tabular}{|c|c|c|}
\hline $\begin{array}{l}\text { Chemical } \\
\text { formula }\end{array}$ & Reservoir oil $\left(z_{i}\right)$ & $\begin{array}{c}\text { Injected } \\
\text { petrleum gas } \\
\left(\mathrm{y}_{\mathrm{i}(\mathrm{a})}\right) \\
\end{array}$ \\
\hline $\mathrm{N}_{2}$ & 0.147 & 0.312 \\
\hline $\mathrm{CO}^{2}$ & 30.721 & 0 \\
\hline $\mathrm{CH}_{4}$ & 8.324 & 72.842 \\
\hline $\mathrm{C}_{2} \mathrm{H}_{6}$ & 7.866 & 8.823 \\
\hline $\mathrm{C}_{3} \mathrm{H} 8$ & 1.674 & 6.124 \\
\hline $\mathrm{i}-\mathrm{C}_{4} \mathrm{H}_{10}$ & 3.572 & 2.225 \\
\hline $\mathrm{n}-\mathrm{C}_{4} \mathrm{H}_{10}$ & 1.294 & 1.742 \\
\hline $\mathrm{i}-\mathrm{C}_{5} \mathrm{H}_{12}$ & 1.652 & 1.286 \\
\hline $\mathrm{n}-\mathrm{C}_{5} \mathrm{H}_{12}$ & 3.123 & 1.661 \\
\hline Pseudo $C_{6}$ & 30.721 & 1.396 \\
\hline Pseudo $\mathrm{C}_{7}$ & - & 1.384 \\
\hline Pseudo $C_{8}$ & - & 1.123 \\
\hline Pseudo $C_{9}$ & - & 1.067 \\
\hline Pseudo $C_{10}$ & - & 0.012 \\
\hline Pseudo $\mathrm{C} 1_{1}$ & - & 0.003 \\
\hline $\mathrm{C}_{12+}$ & - & \\
\hline $\mathrm{C}_{7+}$ & 41.627 & \\
\hline $\begin{array}{c}\text { Molar mass. } \\
\mathrm{g} / \mathrm{mol}\end{array}$ & 133.235 & 27,26 \\
\hline
\end{tabular}


The oil's component composition with regards to the first condition (P1, T1) at the gas injection depth is determined by the following algorithm (Fig 1.).

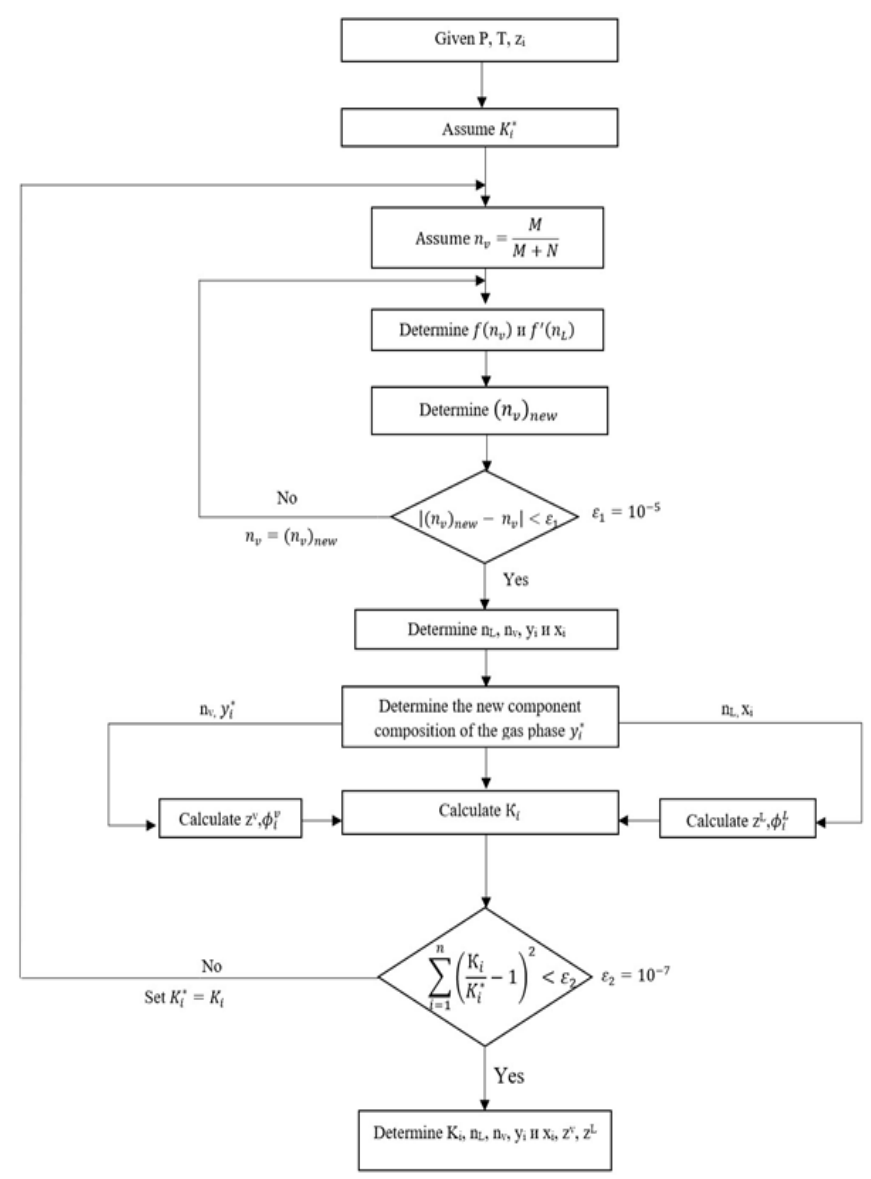

Figure 1 - The complete algorithm to determine changes in the oil's component composition during the produced petroleum gas injection.

$$
\begin{aligned}
& K_{i}=\frac{p_{c i}}{p} \exp \left[5,37\left(1+\omega_{i}\right)\left(1-\frac{T_{c i}}{T}\right)\right] \\
& M=\sum_{i}\left[z_{i}\left(K_{i}-\frac{1}{2}\right)\right] \\
& N=\sum_{i}\left[z_{i}\left(\frac{1}{K_{i}+1}-\frac{1}{2}\right)\right]
\end{aligned}
$$

The Tc, Pc, $\omega$ of component $\mathrm{Cn}+$ are determined by: where $T_{c i}$ - critical temperature of $\mathrm{i}$-component, $\mathrm{P}_{\mathrm{ci}}$ critical pressure of $\mathrm{i}$-component, $\omega$ - acentric factor, $\mathrm{M}_{\mathrm{i}} \mathrm{Y}_{\mathrm{i}}$ molecular weight and specific gravity of the pseudo-component with i carbon atoms. $\mathrm{x}_{\mathrm{i}}$ - component composition of the liquid phase of $\mathrm{i}$ - component

$$
x_{i}=\frac{z_{i}}{n_{L}+n_{v} K_{i}}
$$

$y_{i}$ - component composition of the gas phase of $i$ - component

$y_{i}=x_{i} K_{i}$

$\mathrm{f}\left(\mathrm{n}_{\mathrm{v}}\right)-$ Gas phase characteristic function:

$$
f\left(n_{v}\right)=\sum_{i} \frac{z_{i}\left(K_{i}-1\right)}{n_{v}\left(K_{i}-1\right)+1}
$$

The derivative is given by:

$$
f^{\prime}\left(n_{v}\right)=-\sum_{i} \frac{z_{i}\left(K_{i}-1\right)^{2}}{\left[n_{v}\left(K_{i}-1\right)+1\right]^{2}}
$$

$\left(n_{v}\right)_{\text {new }}$ - the new molar fraction of the gas phase:

$$
\left(n_{v}\right)_{\text {new }}=n_{v}-\frac{f\left(n_{v}\right)}{f^{\prime}\left(n_{v}\right)}
$$

$\mathrm{y}_{\mathrm{i}}{ }^{*}$ - the new component composition of the gas phase of $\mathrm{i}$ - component considered the injected petroleum gas The new component composition of the gas phase is determined the authors [2]:

$y_{i}^{*}=\frac{y_{i(g)} a+y_{i} n_{v}}{\left(n_{v}+a\right)}$

$\mathrm{y}_{\mathrm{i}(\mathrm{g})}$ - component composition of the gas phase of $\mathrm{i}-$ component included in the injected petroleum gas; a the ratio of moles of injected gas to moles of oil per unit time: Subsequently, the binary interaction coefficients are determined according to the following rules:

$k_{i j}<k_{i(j+1)}$

$$
k_{(i+1) j}<k_{i j}
$$

$T_{c i}=128,874105889\left(\frac{M_{i}}{\gamma_{i}}\right)^{0,351579776}-0,195982021\left(\frac{M_{i}}{\gamma_{i}}\right)-129,660666440$

$P_{c i}=219,45331604\left(\frac{M_{i}}{\gamma_{i}}\right)^{-0,885326626}-0,000734065716\left(\frac{M_{i}}{\gamma_{i}}\right)+0,34215749907$

$\omega_{c i}=0,279354619 \ln \left(\frac{M_{i}}{\gamma_{i}}\right)+0,00141973\left(\frac{M_{i}}{\gamma_{i}}\right)-1,243207091$ 
$k_{i i}=0$

$k_{i j}=k_{j i}$

For mixtures containing gas component $\mathrm{N}_{2}, \mathrm{CO}_{2}$ and $\mathrm{CH}_{4}$

$k_{i j}=\delta_{2} T_{r j}^{2}+\delta_{1} T_{r j}+\delta_{0}$

where:

$\mathrm{i}$ - $\mathrm{i}$ stands for the components $\mathrm{CH}_{4}, \mathrm{CO}_{2}$, or $\mathrm{N}_{2}$ and $\mathrm{j}$ stands for the other hydrocarbons, $T_{r}$ - reduced temperature, $T_{r}=T / T_{c}$

For $\mathrm{N}_{2}$-hydrocarbons:

$\delta_{0}=0,1751787-0,7043 \log \left(\omega_{j}\right)-0,862066\left[\log \left(\omega_{i}\right)\right]^{2}$

$\delta_{1}=-0,584474+1,328 \log \left(\omega_{j}\right)+2,035767\left[\log \left(\omega_{i}\right)\right]^{2}$

$\delta_{2}=2,257079+7,869765 \log \left(\omega_{j}\right)+13,50466\left[\log \left(\omega_{i}\right)\right]^{2}+8,3864\left[\log \left(\omega_{i}\right)\right]^{3}(20)$

For $\mathrm{CO}_{2}$-hydrocarbons:

$\delta_{0}=-0,01664-0,37283 \log \left(\omega_{j}\right)+1,31757\left[\log \left(\omega_{i}\right)\right]^{2}$

$\delta_{1}=0,48147+3,35342 \log \left(\omega_{j}\right)-1,0783\left[\log \left(\omega_{i}\right)\right]^{2}$

$\delta_{2}=-0,4114-3,5072 \log \left(\omega_{j}\right)-0,78798\left[\log \left(\omega_{i}\right)\right]^{2}$

For $\mathrm{CO}_{2}$-hydrocarbons:

$\delta_{0}=0,4025636+0,1748927 \log \left(\omega_{j}\right)$

$\delta_{1}=-0,94812-0,6009864 \log \left(\omega_{j}\right)$

$\delta_{2}=0,741843368+0,441775 \log \left(\omega_{j}\right)$

Utilizing the method suggested by the authors [48] to determine the binary interaction coefficients between hydrocarbon components heavier than methane

$k_{C_{n}-C_{n+}}=0,8 k_{C_{(n-1)}-C_{n+}}$

For example:

$k_{C_{2}-C_{n+}}=0,8 k_{C_{1}-C_{n+}}$

$k_{C_{3}-C_{n+}}=0,8 k_{C_{2}-C_{n+}}$

The remaining $k_{y}$ is determined by:

$k_{i j}=k_{i-C_{n+}}\left[\frac{\left(M_{j}\right)^{5}-\left(M_{i}\right)^{5}}{\left(M_{C_{n+}}\right)^{5}-\left(M_{i}\right)^{5}}\right]$
For example:

$k_{C_{3}-C_{4}}=k_{C_{3}-C_{n+}}\left[\frac{\left(M_{C_{4}}\right)^{5}-\left(M_{C_{3}}\right)^{5}}{\left(M_{C_{n+}}\right)^{5}-\left(M_{C_{3}}\right)^{5}}\right]$

\section{Determination of the compressibility}

factor of the phases

The authors [48] proposed the following equation of state:

$p=\frac{R T}{V-b}-\frac{a \alpha}{(V+b)-b(V-b)}$

$a=0,45724 \frac{R^{2} T_{c}^{2}}{p_{c}}$

$b=0,07780 \frac{R T_{c}}{p_{c}}$

$\alpha=\left[1+m\left(1-\sqrt{T_{r}}\right]^{2}\right.$

$T_{r}=T / T_{c}$

$m=0,3796+1,5422 \omega-0,2699 \omega^{2}$

with the acentric values $\omega<0,49$

$m=0,379642+1,48503 \omega-0,1644 \omega^{2}+0,016667 \omega^{3}$

with the acentric values $>0,49$

Rearranging equation (29) into the compressibility factor form gives:

$Z^{3}+(B-1) Z^{2}+\left(A-3 B^{2}-2 B\right) Z-\left(A B-B^{2}-B^{3}\right)=0$

where

$A=\frac{(a \alpha)_{m} P}{R^{2} T^{2}}$

$B=\frac{b_{m} P}{R T^{2}}$

In this work, we study the effect of injected gas on the component composition of the fluid. For the gas phase, taking into account $\mathrm{y}_{i}{ }^{*}$ gives:

$(a \alpha)_{m}=\sum_{i} \sum_{j}\left[y_{i}^{*} y_{j}^{*} \sqrt{a_{i} a_{j} \alpha_{i} \alpha_{j}}\left(1-k_{i j}\right)\right]$ 
$b_{m}=\sum_{i}\left[y_{i}^{*} b_{i}\right]$

$\ln \phi_{i}^{v}=\frac{b_{i}\left(Z^{v}-1\right)}{b_{m}}-\ln \left(Z^{v}-B\right)-\frac{A}{2 \sqrt{2} B}\left[\frac{2 \psi_{i}}{(a \alpha)_{m}}-\frac{b_{i}}{b_{m}}\right] \ln \left[\frac{Z^{v}+(1+\sqrt{2}) B}{Z^{v}-(1-\sqrt{2}) B}\right]$

For the liquid phase:

$$
\begin{aligned}
& (a \alpha)_{m}=\sum_{i} \sum_{j}\left[x_{i} x_{j} \sqrt{a_{i} a_{j} \alpha_{i} \alpha_{j}}\left(1-k_{i j}\right)\right] \\
& b_{m}=\sum_{i}\left[x_{i} b_{i}\right]
\end{aligned}
$$

Parameters $A$ and $B$ in calculations for the gas and liquid phases are denoted respectively: $A_{v}, B_{v}$ and $A_{L}, B_{L}$. Solving the cubic equation (36) applying parameters $A$, $B_{v}$ for gas phase, the largest positive root gives the compressibility factor of the gas phase: $Z^{\mathrm{v}}$ - largest positive root Solving the cubic equation (36) applying parameters $A_{L}, B_{L}$ for liquid phase, the smallest positive root gives the compressibility factor of the liquid phase: $Z^{L}$ - smallest positive root

\section{Determination of the equilibrium ratio "Ki"}

Regarding the literature reviews, when studying the wax deposition in the production of a gas-lift well, the fugacity must be considered. This paper developed a fully complete algorithm based on the previous model proposed by the authors [2]. It is known that fugacity is a function of pressure. Besides, the fugacity may be perceived as a vapor pressure adjusted to accurately illustrate the molecules' tendency from one phase to escape into another. Thus, the fugacity coefficient of the i- component in a mixture is a function of the system pressure, mole fraction, and fugacity of the individual components. Furthermore, the $K_{i}$ ratio represents the interaction between phases and has a great impact on the gas properties as a whole and $\mathrm{K}_{\mathrm{i}}$ can be described as the following equation:

$$
K_{i}=\frac{\phi_{i}^{L}}{\phi_{i}^{v}}
$$

Where $\phi_{i}^{L}, \phi_{i}^{v} \quad$ - fugacity coefficients of liquid phase and gas phase correspondingly. Applying the calculated composition of the liquid phase, $\mathrm{xi}$, from flash calculation to determine the fugacity coefficient for each component in the liquid phase by applying the following equation:

$$
\ln \phi_{i}^{L}=\frac{b_{i}\left(Z^{L}-1\right)}{b_{m}}-\ln \left(Z^{L}-B\right)-\frac{A}{2 \sqrt{2} B}\left[\frac{2 \psi_{i}}{(a \alpha)_{m}}-\frac{b_{i}}{b_{m}}\right] \ln \left[\frac{Z^{L}+(1+\sqrt{2}) B}{Z^{L}-(1-\sqrt{2}) B}\right]
$$

where

$$
\psi_{i}=\sum_{j}\left[x_{j} \sqrt{a_{i} a_{j} \alpha_{i} \alpha_{j}}\left(1-k_{i j}\right)\right]
$$

Applying the calculated new composition of the gas phase, $\mathrm{y}_{\mathrm{i}}^{*}$, considering the injected petroleum gas, to determine the fugacity coefficient $\phi_{i}^{v}$ for each component in the gas phase by applying the following equation: where $\psi_{i}=\sum_{j}\left[y_{j}^{*} \sqrt{a_{i} a_{j} \alpha_{i} \alpha_{j}}\left(1-k_{i j}\right)\right]$

For the first flash calculation with regards to the initial conditions $\left(P_{1}, T_{1}\right)$ we observed molar fraction of the gas phase $n_{v 2}$ and liquid phase $n_{v 1}$ (assume $n_{v 1}+n_{v 1}=$ 1 which is the initial mole of the mixture) as well as the component composition of the liquid phase xi1 and gas phase $y_{i}^{*}$ (considering injected petroleum gas). Having done that, when calculating the component composition for the second condition $\left(P_{2}, T_{2}\right)$, we assumed the component composition of the liquid phase $\mathrm{x}_{\mathrm{i} 1}$ obtained from the calculation at the first condition $\left(P_{1}, T_{1}\right)$ as the initial total composition zi for the second condition $\left(\mathrm{P}_{2}, \mathrm{~T}_{2}\right)$ and the number of mole of the mixture remains constant (1 mole). Following this, the flash calculation for the second condition was performed, receiving the assumed molar fraction of the gas phase $n_{\mathrm{v} 2(\mathrm{a})}$ and liquid phase $\mathrm{n}_{\mathrm{L} 2(\mathrm{a})}$. The actual number of moles of the liquid phase is calculated by:

$n_{L 2}=1 \cdot n_{L 1} \cdot n_{L 2(a)}$

The previous procedure is repeated for each condition $\left(P_{3}, T_{3}\right),\left(P_{n}, T_{n}\right)$ :

$n_{L n}=\prod_{i=1}^{n} n_{L i}$

For gas phase: $n_{v n}=1-\prod_{i=1}^{n} n_{L i}$

With $n_{L i}, n_{V V}, K_{i}$ for each conditions, it is possible to calculate $x_{i}$ and gas phase $y_{i}^{*}$. The component composition of gas and liquid phases for all the studied conditions ( $P$, $\mathrm{T}$ ) is presented in table 2 . In this study, the results have been obtained using the complete algorithm, developed based on the previous one proposed by the authors [2], which provides highly accurate results with an extensive the WAT. consideration of all key mentioned factors that influence 
Table 2: Results from the calculation for the component compositions applying the complete algorithm

\begin{tabular}{|c|c|c|c|c|c|c|c|c|c|c|c|}
\hline \multirow{3}{*}{$\begin{array}{l}\text { Chemical } \\
\text { formula }\end{array}$} & \multirow{3}{*}{$\begin{array}{c}\text { Reservoir } \\
\text { oil }\end{array}$} & \multicolumn{10}{|c|}{ Component composition (mole fraction, \%) } \\
\hline & & \multicolumn{2}{|c|}{$12 \mathrm{MPa}$} & \multicolumn{2}{|c|}{$10 \mathrm{MPa}$} & \multicolumn{2}{|c|}{$8 \mathrm{MPa}$} & \multicolumn{2}{|c|}{$4 \mathrm{MPa}$} & \multicolumn{2}{|c|}{$1.5 \mathrm{MPa}$} \\
\hline & & $\begin{array}{l}\text { Liq. } \\
\text { Phase }\end{array}$ & $\begin{array}{l}\text { Gas } \\
\text { phase }\end{array}$ & $\begin{array}{l}\text { Liq. } \\
\text { phase }\end{array}$ & $\begin{array}{l}\text { Gas } \\
\text { phas }\end{array}$ & $\begin{array}{l}\text { Liq. } \\
\text { phase }\end{array}$ & $\begin{array}{l}\text { Gas } \\
\text { phas }\end{array}$ & $\begin{array}{l}\text { Liq. } \\
\text { phase }\end{array}$ & $\begin{array}{l}\text { Gas } \\
\text { phas }\end{array}$ & $\begin{array}{l}\text { Liq. } \\
\text { phase }\end{array}$ & $\begin{array}{l}\text { Gas } \\
\text { phas }\end{array}$ \\
\hline $\mathrm{N}_{2}$ & 0.147 & 0.092 & 0.319 & 0.047 & 0.316 & 0.006 & 0.312 & 0.000 & 0.306 & 0.000 & 0.301 \\
\hline $\mathrm{CO}_{2}$ & 0.000 & 0.000 & 0.000 & 0.000 & 0.000 & 0.000 & 0.000 & 0.000 & 0.000 & 0.000 & 0.000 \\
\hline $\mathrm{CH}_{4}$ & 30.721 & 25.612 & 72.913 & 19.747 & 72.865 & 12.528 & 72.664 & 0.000 & 71.261 & 0.000 & 69.263 \\
\hline $\mathrm{C}_{2} \mathrm{H}_{6}$ & 8.324 & 8.165 & 8.878 & 7.659 & 8.919 & 6.640 & 9.074 & 2.586 & 9.577 & 0.280 & 9.704 \\
\hline $\mathrm{C}_{3} \mathrm{H}_{8}$ & 7.866 & 7.709 & 6.134 & 7.772 & 6.158 & 7.581 & 6.258 & 5.319 & 6.816 & 2.453 & 7.680 \\
\hline $\mathrm{i}-\mathrm{C}_{4} \mathrm{H}_{10}$ & 1.674 & 1.663 & 2.199 & 1.730 & 2.197 & 1.776 & 2.193 & 1.559 & 2.276 & 1.000 & 2.496 \\
\hline$n-C_{4} H_{10}$ & 3.572 & 3.516 & 1.745 & 3.702 & 1.751 & 3.875 & 1.781 & 3.677 & 1.977 & 2.641 & 2.454 \\
\hline $\mathrm{i}-\mathrm{C}_{5} \mathrm{H}_{12}$ & 1.294 & 1.320 & 1.269 & 1.421 & 1.267 & 1.538 & 1.260 & 1.668 & 1.296 & 1.483 & 1.417 \\
\hline $\mathrm{n}-\mathrm{C}_{5} \mathrm{H}_{12}$ & 1.652 & 1.707 & 1.637 & 1.845 & 1.634 & 2.013 & 1.623 & 2.249 & 1.660 & 2.099 & 1.787 \\
\hline Pseudo $C_{6}$ & 3.012 & 3.171 & 1.377 & 3.503 & 1.374 & 3.942 & 1.364 & 4.904 & 1.389 & 5.230 & 1.454 \\
\hline Pseudo $C_{7}$ & 365 & 8.945 & 1.362 & 10.060 & 1.359 & 11.578 & 1.344 & 15.334 & 1.346 & 17.162 & 1.361 \\
\hline Pseudo $\mathrm{C}_{8}$ & 6.661 & 6.695 & 1.103 & 7.530 & 1.100 & 8.666 & 1.085 & 11.478 & 1.073 & 12.845 & 1.068 \\
\hline Pseudo $\mathrm{C}_{9}$ & 4.323 & 5.124 & 1.048 & 5.763 & 1.044 & 6.633 & 1.027 & 8.785 & 1.009 & 9.832 & 1.001 \\
\hline Pseudo $C_{10}$ & 3.545 & 3.923 & 0.012 & 4.412 & 0.012 & 5.077 & 0.011 & 6.725 & 0.011 & 7.526 & 0.011 \\
\hline${\text { Pseudo } C_{11}}$ & 2.765 & 3.003 & 0.003 & 3.377 & 0.003 & 3.887 & 0.003 & 5.148 & 0.003 & 5.761 & 0.003 \\
\hline $\mathrm{C}_{12+}$ & 17.079 & 19.356 & 0.000 & 21.432 & 0.000 & 24.259 & 0.000 & 30.569 & 0.000 & 31.687 & 0.000 \\
\hline
\end{tabular}

Having obtained the results of the component composition of gas and liquid phases for all the studied conditions, it is possible to determine the WAT using wellknown software products, such as Multiflash 6.1, Flow Assurance OLGA, LedaFlow Software (in this work the authors used Multiflash 6.1). The initial data for modeling is the obtained result by using the complete algorithm (Fig.1). According to the description of the program, the accuracy of a calculation depends on how we characterized the initial data. Moreover, Multiflash 6.1 is based on the well-known wax model proposed by author [48], in which the properties of the fluid and gas phase as well as the interaction between them are taken into account. Thus, by fully characterizing the properties of gas and liquid phases as well as their changes in different conditions $\left(P_{n}, T_{n}\right)$ using the algorithm, it is possible to acquire highly accurate results of the WATs (Table 3 ). Organic wax crystals will be formed when the flow temperature drops to the WAT, therefore, the depth of wax formation corresponds to the intersection of the distribution curves of the wax appearance temperature and the flow temperature (Fig. 4).

Table 3: Changes of the wax appearance temperature in different conditions

\begin{tabular}{|c|c|c|c|c|c|c|}
\hline Parameters & \multicolumn{5}{|c|}{ Value } \\
\hline Pressure (MPa) & 13.5 & 12.0 & 10.0 & 8.0 & 4.0 & 1.5 \\
\hline WAT (OC) & 55.012 & 54.196 & 52.923 & 50.845 & 48.431 & 47.388 \\
\hline
\end{tabular}

Figure 2 shows the changes in the dependences of the WAT on the pressure using the old model proposed by the authors [2] and the complete one. The difference between the two dependence lines has been observed. It can be explained that in the new complete model, we have taken into account additional factors that influence the wax formation process, such as the amount of compressed injection gas, properties of the multiple phases, and interactions between phases. One of the key factors is fugacity, which is a function of the system pressure, mole fraction, and fugacity of the individual components. In addition, in the previous model, the equilibrium ratio $\mathrm{Ki}$ was obtained by applying the Standing correlation, which might be less accurate for different conditions of wax formation. Nonetheless, in the new model, the K-value has been obtained by considering all the changes in the component composition of the liquid and gas phases during gas injection that directly affect the K- value (equation $44,45)$. In addition, when APG is injected into the well, the oil is heavily saturated with gas. The gas acts as a 
solvent to reduce WAT. In this regard, the dependence curve of the complete model is below the curve corresponding to the previous model.

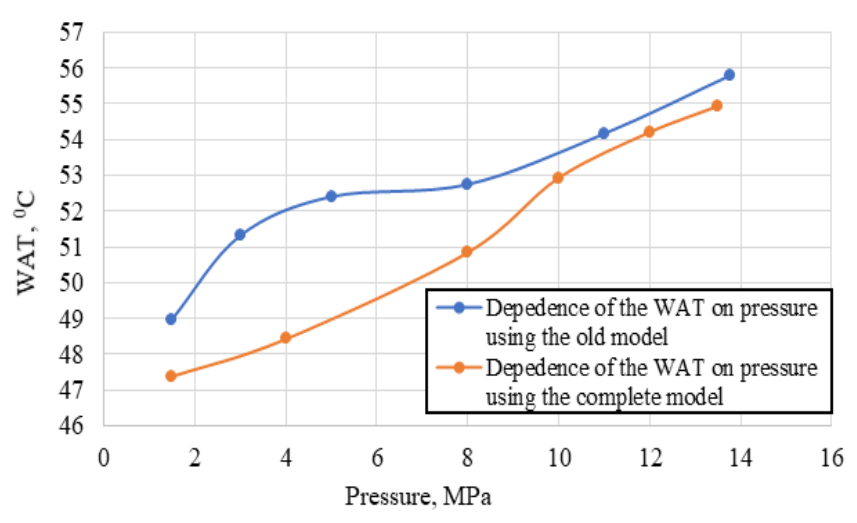

Figure 2: Comparison of the WAT calculation using the different models

\section{A comprehensive solution to preventing the formation of wax deposition in gas-lift wells}

Wax prevention is of paramount importance in the petroleum industry, especially during production in gas-lift wells. There are several well-known methods used to handle wax formation problems such as mechanical-removal methods, chemical inhibitors, thermal techniques, chemical solvents, and other methods. Although, there are several methods that have been applied to handle the wax formation problem in recent decades, questions concerning their economic viability as well as their effectiveness remain relevant. Moreover, the effect of the component composition of fluids on the wax formation process has been studied by a number of researchers [49-52]. The authors showed that the light-end hydrocarbon components $\left(\mathrm{C}_{1}-\mathrm{C}_{4}\right)$ and the remaining components (heavy fractions) play completely different roles in wax crystallization and as a result, they have a great impact on the WAT. Consequently, based on the mentioned points, the authors of this paper have proposed a comprehensive technological scheme for a method of mitigating wax deposit formation in the tubing strings during gas-lift well operation. The proposed method to prevent the formation of wax deposition in gas-lift wells is carried out in the following sequence (Fig. 3). Associated petroleum injection gas (hereinafter referred to as APIG), previously filtered to remove hydrogen sulfide $\left(\mathrm{H}_{2} \mathrm{~S}\right)$ and carbon dioxide $\left(\mathrm{CO}_{2}\right)$, is considered as a working agent for the gas-lift well. The APIG is selected with a certain composition, depending on the composition and properties of well products, their changes when mixed with the working agent, planed flow rate, and gas oil ratio in order to reduce the WAT and the intensity of organic wax formation. The composition and the amount of the APIG are selected as the following steps:Initially, the option of injecting treated APIG without changing its hydrocarbon composition, including light fractions from $\mathrm{CH}_{4}$ to $\mathrm{C}_{4} \mathrm{H}_{10}$ and heavier fractions from $\mathrm{C}_{5} \mathrm{H}_{12}$ to $\mathrm{C}_{11} \mathrm{H}_{24}$, was chosen. Next, for this option, the WAT and the depth of wax formation in the well were determined, taking into account the change in the composition of oil when injecting APIG applying the proposed algorithm (Fig. 1). The obtained value of the WAT is considered as the starting point for comparison with subsequent options. The next step is to change the ratio of light and heavy fractions of the APIG and carry out the calculation according to the proposed algorithm, a new value of the WAT is obtained.

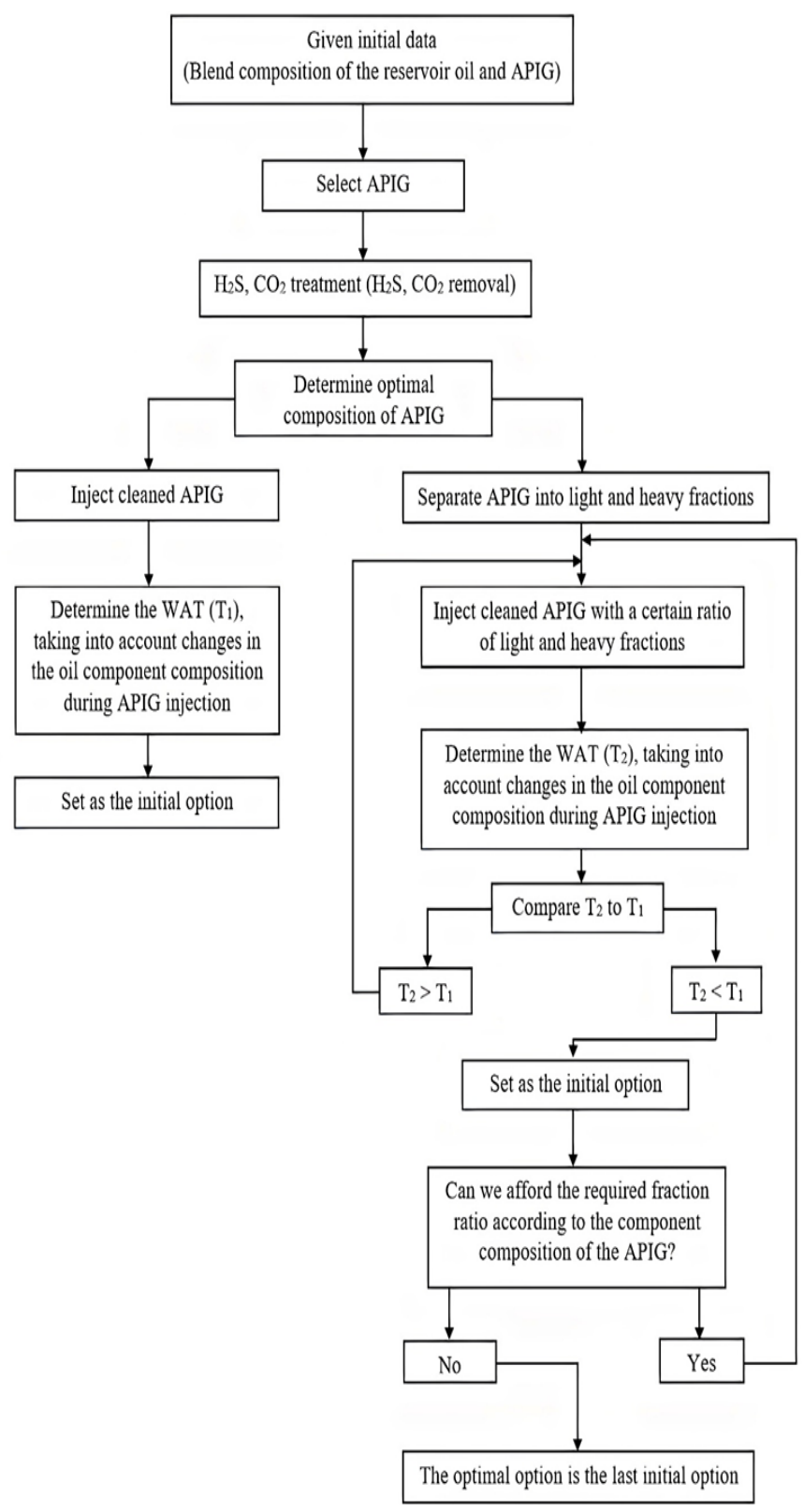

Figure 3: Technological scheme of the proposed method

Having repeated the procedure for various ratios of light and heavy fractions, it is possible to determine the optimal option for the APIG, based on the required flow rate of the working agent and the lowest value of the WAT. Table 4 shows the result of determining the optimal composition of the APIG. 
Table 4:The result of determining the optimal composition of the APIG

\begin{tabular}{|c|c|c|}
\hline $\begin{array}{c}\text { Chemical } \\
\text { formula }\end{array}$ & $\begin{array}{c}\text { The initial option } \\
\text { of the APIG }\end{array}$ & $\begin{array}{c}\text { The optimal } \\
\text { option of the } \\
\text { APIG }\end{array}$ \\
\hline $\mathrm{N}_{2}$ & 0.312 & 0.2805 \\
\hline $\mathrm{CO}_{2}$ & 0 & 0 \\
\hline $\mathrm{CH}_{4}$ & 72.842 & 67.5571 \\
\hline $\mathrm{C}_{2} \mathrm{H}_{6}$ & 8.823 & 8.2223 \\
\hline $\mathrm{C}_{3} \mathrm{H}_{8}$ & 6.124 & 5.8488 \\
\hline $\mathrm{i}-\mathrm{C}_{4} \mathrm{H}_{10}$ & 2.225 & 1.6322 \\
\hline $\mathrm{n}-\mathrm{C}_{4} \mathrm{H}_{10}$ & 1.742 & 1.9592 \\
\hline $\mathrm{i}-\mathrm{C}_{5} \mathrm{H}_{12}$ & 1.286 & 3.2435 \\
\hline $\mathrm{n}-\mathrm{C}_{5} \mathrm{H}_{12}$ & 1.661 & 2.3110 \\
\hline Pseudo $\mathrm{C}_{6}$ & 1.396 & 2.5441 \\
\hline Pseudo $\mathrm{C}_{7}$ & 1.384 & 2.4513 \\
\hline Pseudo $\mathrm{C}_{8}$ & 1.123 & 1.9341 \\
\hline Pseudo $\mathrm{C}_{9}$ & 1.067 & 1.9887 \\
\hline Pseudo $\mathrm{C}_{10}$ & 0.012 & 0.0200 \\
\hline Pseudo $\mathrm{C}_{11}$ & 0.003 & 0.0073 \\
\hline
\end{tabular}

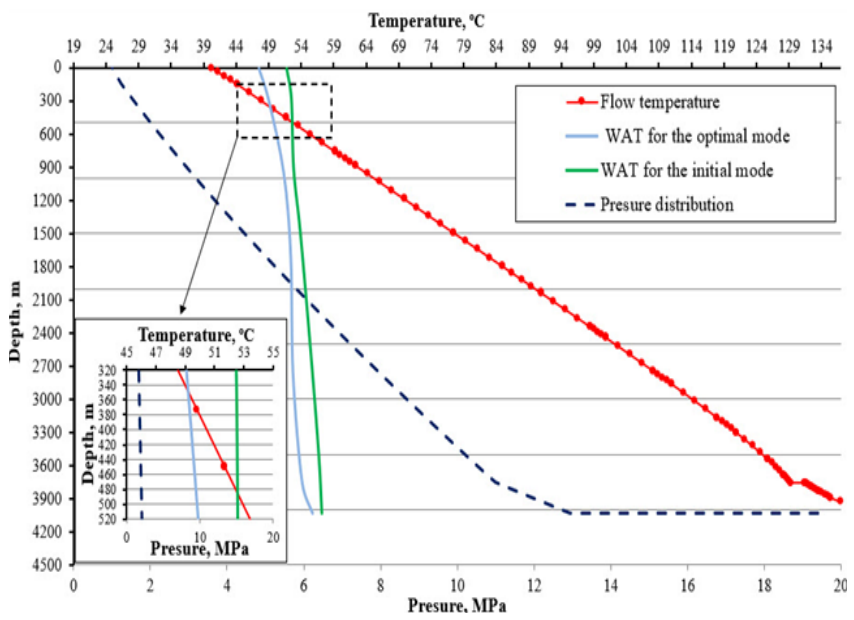

Figure 4: Change in the depth of formation of wax in the well tubing with the optimal composition for the associated petroleum injection gas.

According to the simulation results, it can be observed that by employing the proposed method of remediating wax deposition in a gas-lift well, the depth corresponding to the onset of the formation of wax deposits has been dramatically decreased from $480 \mathrm{~m}$ to $340 \mathrm{~m}$ (Fig. 4). The results have proven to be effective in reducing the WAT (by 4 0C) and the depth of wax formation (by 140 $m)$. As a result, it enables the injection of APIG at lower pressures in comparison to traditional gas-lift methods, in which the optimal composition of APIG is not considered. Thus, the method offers potential solutions for handling wax deposition problems in accordance with economic estimations and can be highly recommended for practical application in terms of mitigating wax formation processes in gas-lift wells.

\section{CONCLUSIONS}

A complete algorithm to determine changes in the oil's component composition during the associated petroleum gas injection has been developed. The obtained results play a pivotal role in studying the wax deposition in gaslift wells. A technological scheme has been developed to prevent wax deposit formation in the tubing strings during gas-lift well operation. After running the simulation, we determined the optimal composition of the associated petroleum injection gas based on the required flow rate of the working agent and the lowest value of the wax appearance temperature. In addition, the simulation shows that by applying the proposed method of mitigating wax deposition in a gas-lift well, the depth corresponding to the onset of the formation of wax deposits in the gas-lift well is dramatically decreased by $140 \mathrm{~m}$ (from $480 \mathrm{~m}$ to $340 \mathrm{~m}$ ). The results have also proven to be effective in reducing the WAT (by $40 \mathrm{C}$ ). Hence, the method is highly recommended for practical application for mitigating wax precipitation in gas-lift wells.

\begin{tabular}{|c|c|}
\hline Abbreviation & Definition \\
\hline ARPD & Asphalt-resin-paraffin deposits \\
\hline WAT & Wax appearance temperature \\
\hline APIG & Associated petroleum injection gas \\
\hline
\end{tabular}

\section{REFERENCES}

1. Sevic, S., \& Branko G. (2017). Simulation of temperature-pressure profiles and wax deposition in gas-lift wells. Chemical Industry and Chemical Engineering Quarterly, Volume 23(4), pp. 537-545. DOI: 10.2298/CICEQ161014006S

2. Nguyen, V.T., Rogachev, M.K., \& Aleksandrov, A.N. (2020). A new approach to improving efficiency of gas-lift wells in the conditions of the formation of organic wax deposits in the Dragon field. Journal of Petroleum Exploration and Production Technology, Volume 10(8), pp. 3663-3672. DOI: 10.1007/ s13202-020-00976-4

3. Khaibullina, K.S., Korobov, G.Y., \& Lekomtsev, A.V. (2020). Development of an asphalt-resin-paraffin deposits inhibitor and substantiation of the technological parameters of its injection into the bottom-hole formation zone. Periódico tchê química, Volume 17(34), pp. 769-781.

4. Drozdov, A.N., \& Gorbyleva, Y.A. (2019). Improving the Operation of Pump-ejector Systems at Varying Flow Rates of Associated Petroleum Gas. Journal of Mining Institute, Volume 238, pp. 415-422. DOI: 10.31897/PMI.2019.4.415 
5. Aguiar, J.I.S., Pontifes, A.A., Nerris, A., Rogers, J., \& Mahmoudkhani, A. (2020). Impact of Solvent Treatments for Asphaltenes on Wax Deposition and an Efficient Alternative with Green Surfactants. Offshore Technology Conference. DOI: 10.4043/30695-MS

6. Goodman, N.T., \& Joshi, N. (2013). A Tale of Two Flowlines - Paraffin Plugging and Remediation. Society of Petroleum Engineers. DOI: 10.2118/166196MS

7. Weingarten, J.S., \& Euchner, J.A. (1988). Methods for predicting wax precipitation and deposition. SPE Production Engineering, pp. 121-126. DOI: 10.2118/15654-PA

8. Mydland, S., Whitson, C.H., Carlsen, M.L., Dahouk, M.M., \& Yusra, I. (2020). Black-Oil and Compositional Reservoir Simulation of Gas-Based EOR in Tight Unconventional. In SPE/AAPG/SEG Unconventional Resources Technology Conference. Unconventional Resources Technology Conference. DOI: 10.15530/ urtec-2020-2765

9. Zheng, S., Saidoun, M., Palermo, T., Mateen, K., \& Fogler, H.S. (2017). Wax deposition modeling with considerations of non-Newtonian characteristics: Application on field-scale pipeline. Energy \& Fuels, Volume 31(5), pp. 5011-5023. DOI: 10.4043/26914MS

10. Thota, S.T., \& Onyeanuna, C.C. (2016). Mitigation of wax in oil pipelines. Int J Eng Res Rev, Volume 4(4), pp. 39-47.

11. White, M., Pierce, K., \& Acharya, T. (2018). A review of wax-formation/mitigation technologies in the petroleum industry. SPE Production \& Operations, Volume 33(03), pp. 476-485. DOI: 10.2118/189447-PA

12. Islamov, S. R., Bondarenko, A. V., \& Mardashov, D. V. (2019). A selection of emulsifiers for preparation of invert emulsion drilling fluids. In Topical Issues of Rational Use of Natural Resources, Volume 2, pp. 487-494.

13. Linh, N.K., Gabov, V.V., \& Lykov, Y.V. (2018). Substantiation of parameters of coal unloading process onto conveyor using shearer drums. IOP Conference Series: Earth and Environmental Science, Volume 194. DOI: $10.1088 / 1755-1315 / 194 / 4 / 042019$

14. Cherepovitsyn, A.E., Lipina, S.A., \& Evseeva, O.O. (2018). Innovative approach to the development of mineral raw materials of the Arctic zone of the Russian Federation. Journal of Mining Institute, Volume 232, pp. 438-444. DOI: 10.31897/PMI.2018.4.438

15. Rogachev, M.K., \& Strizhnev, K.V. (2006). Fighting complications in oil production. Nedra, 296 p.

16. Decker, K., \& Sutton, R.P. (2018). Gas Lift Annulus Pressure. In SPE Artificial Lift Conference and Exhibition-Americas. Society of Petroleum Engineers. DOI: 10.2118/190929-MS
17. Golubev, I.A., Golubev, A.V., \& Laptev, A.B. (2020). Practice of using the magnetic treatment devices to intensify the processes of primary oil treating. Journal of Mining Institute, Volume 245, pp. 554-560. DOI: 10.31897/PMI.2020.5.7

18. Kopteva, A.V., Dementyev, A., \& Koptev, V. (2021). Analysis of the Structure of Viscous Oil Flow for the Development of a System to Prevent the Formation of Paraffin Deposits in Pipelines. In Materials Science Forum, Volume 1022, pp. 42-51.

19. Aslanov, H., Novruzov, A., \& Harun, A. (2019). Managing Wax-Deposition Risks in Oil Subsea Pipelines by Integrating Wax Modeling and Pigging Performance. SPE Production \& Operations, Volume 34(03), pp. 625-634. DOI: 10.2118/194506-PA

20. Fleyfel, F., Meng, W., \& Hernandez, O. (2004). Production of Waxy Low Temperature Wells with Hot Gas Lift. SPE Annual Technical Conference and Exhibition. Society of Petroleum Engineers. DOI: 10.2118/89853-MS

21. Shedid, S.A., \& Yakoot, M.S. (2016). Simulation study of technical and feasible gas lift performance. International Journal of Petroleum Science and Technology, Volume 10(1), pp. 21-44.

22. Zhao, Y., Limb, D., \& Zhu, X. (2017). A study of wax deposition in pipeline using thermal hydraulic model. In 18th International Conference on Multiphase Production Technology. BHR Group.

23. Feder, J. (2019). Gas Lift Operations Require Accurate Predictions of Downhole Annulus Pressure. Journal of Petroleum Technology, Volume 71(03), pp. 65-67. DOI: 10.2118/0319-0065-JPT

24. Morenov, V., \& Leusheva, E. (2017). Development of Drilling Mud Solution for Drilling in Hard Rocks. International Journal of Engineering, Volume 30(4), pp. 620-626. DOI: 10.5829/idosi.ije.2017.30.04a.22

25. Islamov, S.R.; Bondarenko, A.V.; Gabibov, A.F.; Mardashov, D.V. Polymer compositions for well killing operation in fractured reservoirs. Advances in Raw Material Industries for Sustainable Development Goals; Taylor \& Francis: London, UK, 2021; pp. 343351.Morenov, V., \& Leusheva, E. (2019). Influence of the solid phase's fractional composition on the filtration characteristics of the drilling mud. International Journal of Engineering, Transactions B: Applications, Volume 32(5), pp. 794-798. DOI: 10.5829/ ije.2019.32.05b.22

26. Hassan, A., Alade, O., Mahmoud, M., \& Al-Majed, A. (2019). A Novel Technique for Removing Wax Deposition in the Production System Using Thermochemical Fluids. Society of Petroleum Engineers. DOI: 10.2118/197323-MS 
27. Santos, H.F.L., Perondi, E.A., Wentz, A.V., Silva Júnior, A.L., Barone, D.A.C., Galassi, M., \& Ferreira, L.H.T. (2020). Annelida, a Robot for Removing Hydrate and Paraffin Plugs in Offshore Flexible Lines: Development and Experimental Trials. Society of Petroleum Engineers. DOI: 10.2118/196015-PA

28. Ilyushin, Y.V., \& Novozhilov, I.M. (2019). Automation of the Paraffin Oil Production Technological Process. In 2019 III International Conference on Control in Technical Systems (CTS), pp. 164-167. IEEE. DOI: 10.1109/CTS48763.2019.8973352

29. Raney, K., Alibek, K., Shumway, M., Karathur, K., Stanislav, T., West, G., \& Jacobs, M. (2019). A Novel Biochemical-Based Paraffin Wax Removal Program Providing Revenue Generation and Asset Enhancement. Society of Petroleum Engineers. DOI: 10.2118/193579-MS

30. Xiu, Z., Dufils, P.-E., Zhou, J., Cadix, A., Hatchman, K., Decoster, T., \& Ferlin, P. (2019). Amphiphilic Wax Inhibitor for Tackling Crude Oil Wax Deposit Challenges. Society of Petroleum Engineers. DOI: 10.2118/193593-MS

31. Miller, A., Smith, R., Dufresne, B., \& Mahmoudkhani, A. (2019). Out with the Old: Developing a New Test Methodology for Paraffin Wax Dispersion and Inhibition Testing. Society of Petroleum Engineers. DOI: 10.2118/193552-MS

32. Islamov, S.R., Bondarenko, A.V., Mardashov, D.V. Substantiation of a well killing technology for fractured carbonate reservoirs. Youth Technical Sessions Proceedings: VI Youth Forum of the World Petroleum Council - Future Leaders Forum; Taylor \& Francis: London, UK, 2019; pp. 256-264

33. Kar, T., \& Firoozabadi, A. (2019). Mitigation of Paraffinic Wax Deposition and the Effect of Brine. Society of Petroleum Engineers. DOI: 10.2118/196032-MS

34. Khormali, A., Moghadasi, R., Kazemzadeh, Y., \& Struchkov, I. (2021). Development of a new chemical solvent package for increasing the asphaltene removal performance under static and dynamic conditions. Journal of Petroleum Science and Engineering, 109066. DOI: 10.1016/j.petrol.2021.109066

35. Coutinho, R., Williams, W., Waltrich, P., Mehdizadeh, P., \& Scott, S. (2017). A model for liquid-assisted gas-lift unloading. In 18th International Conference on Multiphase Production Technology. BHR Group.

36. Rogachev, M.K., Nguyen Van, T., Aleksandrov, A.N. Technology for Preventing the Wax Deposit Formation in Gas-Lift Wells at Offshore Oil and Gas Fields in Vietnam. Energies 2021, 14, 5016. DOI:10.3390/ e14165016
37. Khormali, A., Sharifov, A.R., \& Torba, D.I. (2018). Experimental and modeling study of asphaltene adsorption onto the reservoir rocks. Petroleum Science and Technology, Volume 36 (18), pp. 1482-1489. DOI: 10.1080/10916466.2018.1496116.

38. Wilson, A. (2018). Novel Polymer Modifications Lead to Next-Generation Pour-Point Depressants. Society of Petroleum Engineers. DOI: 10.2118/0918-0114JPT

39. 39. Nwankwo, K.O., Chikwekwem, C.J., \& Nwankwo, P.C. (2018). Simultaneous Flow Assurance and Production Optimization Using Chemical Paraffin Inhibition Method. Society of Petroleum Engineers. DOI: 10.2118/193515-MS

40. Sultanbekov, R., Islamov, S., Mardashov, D., Beloglazov, I.,Hemmingsen, T. Research of the Influence of Marine Residual Fuel Composition on Sedimentation Due to Incompatibility. J. Mar. Sci. Eng. 2021, 9, 1067. DOI: 10.3390/jmse9101067Macary,

41. Khaibullina, K.S., Sagirova, L.R., \& Sandyga, M.S. (2020). Substantiation and selection of an inhibitor for preventing the formation of asphalt-resin-paraffin deposits. Periodico Tche Quimica, Volume 17(34), pp. 541-551.

42. Li, W., Huang, Q., Wang, W., Ren, Y., Dong, X., Zhao, Q., \& Hou, L. (2019). Study on Wax Removal During Pipeline-Pigging Operations. Society of Petroleum Engineers. DOI: 10.2118/194010-PA

43. Sultanbekov, R., Beloglazov, I., Islamov, S., Ong, M.C. Exploring of the Incompatibility of Marine Residual Fuel: A Case Study Using Machine Learning Methods. Energies 2021, 14, 8422. DOI: 10.3390/ en14248422

44. Olajire, A.A. (2021). Review of wax deposition in subsea oil pipeline systems and mitigation technologies in the petroleum industry. Chemical Engineering Journal Advances. Vol. 6, pp. 100-104. DOI: 10.1016/j.ceja.2021.100104

45. Behbahani, T.J., Beigi, A.A.M., Taheri, Z., \& Ghanbari, B. (2015). Investigation of wax precipitation in crude oil: Experimental and modeling. Petroleum, Volume 1(3), pp. 223-230. DOI: 10.1016/j. petIm.2015.07.007

46. Brown, T.S., Niesen, V.G., \& Erickson, D.D. (1994). The effects of light ends and high pressure on paraffin formation. In SPE annual technical conference and exhibition. Society of Petroleum Engineers.

47. Du, F., Nojabaei, B., \& Johns, R.T. (2018). A blackoil approach to model produced gas injection for enhanced recovery of conventional and unconventional reservoirs. In SPE Annual Technical Conference and Exhibition. Society of Petroleum Engineers. 
DOI: 10.2118/191454-MS

48. Pedersen, K.S., Fredenslund, A., \& Thomassen, P. (1989). Properties of oils and natural gases. Gulf Pub Co, Volume 5, $385 \mathrm{p}$.

49. Hosseinipour, A., Sabil, K.M., Arya Ekaputra, A., Japper, A.B., \& Ismail, L.B. (2014). The impact of the composition of the crude oils on the wax crystallization. In Applied Mechanics and Materials, Volume 625, pp. 196-200. DOI: 10.4028/www.scientific.net/ amm.625.196

50. Aleksandrov, A.N., Rogachev, M.K., Van, T.N., Kishchenko, M.A., \& Kibirev, E.A. (2019). Simulation of organic solids formation process in high-wax formation oil. Topical Issues of Rational Use of Natural Resources, Volume 2, pp. 779-790.

51. Taheri-Shakib, J., Rajabi-Kochi, M., Kazemzadeh, E., Naderi, H., \& Shekarifard, A. (2018). A comprehensive study of the impact of wax compositions on the wax appearance temperature (WAT) of some Iranian crude oils: an experimental investigation. Journal of Petroleum Science and Engineering, Volume 165, pp. 67-80.

52. Xie, Y., Meng, J., \& Chen, D. (2021). Wax deposition law and OLGA-Based prediction method for multiphase flow in submarine pipelines, Petroleum. DOI: 10.1016/j.petlm.2021.03.004. 